\title{
Osteoporosis in urban post-menopausal women of the Philippines: prevalence and risk factors
}

\author{
S. Miura • O. L. Saavedra $\cdot$ S. Yamamoto
}

Received: 4 November 2007 / Accepted: 29 May 2008 / Published online: 5 September 2008

(C) The Author(s) 2008. This article is published with open access at Springerlink.com

\begin{abstract}
Summary The prevalence of osteoporosis was assessed among post-menopausal women dwelling in an urban community of Davao, Philippines using quantitative ultrasonic bone densitometry and its predictors were investigated. The prevalence of osteoporosis was $19.8 \%$. Advancing age, lower body weight, and higher educational attainment were identified as the independent predictors of osteoporosis.

Introduction This cross-sectional study assessed the prevalence of osteoporosis among post-menopausal women dwelling in an urban community of the Philippines and investigated the risk factors for osteoporosis using a quantitative ultrasonic bone densitometer.

Methods The study site was an area with high population density in Davao, the Philippines. Data collection was based on a structured questionnaire interview, and measurements of body size and speed of sound (SOS) at the calcaneus. The SOS T-score was calculated using the young adult mean (YAM) SOS based on data from 905 women aged 20 years and over residing in the community. The data
\end{abstract}

\footnotetext{
S. Miura $\cdot$ S. Yamamoto

International Nutrition, Graduate School of Humanities

\& Sciences, Ochanomizu University,

Tokyo, Japan

O. L. Saavedra

Philippine Obstetrical and Gynecological Society,

Davao, Philippines

S. Miura $(\bowtie)$

International Nutrition, Ochanomizu University,

2-1-1 Ohtsuka, Bunkyo-ku,

Tokyo zip 112-8610, Japan

e-mail: miura-shoko@umin.ac.jp
}

for 339 post-menopausal women were analyzed to identify the prevalence of osteoporosis and its predictors in this study. The predictors of osteoporosis were determined by logistic regression analysis.

Results The majority of the women lived on low-incomes. The prevalence of osteoporosis was $19.8 \%$ in postmenopausal women. Age in 1 year increments (odds ratio [OR] 1.168), body weight (OR 0.954), and duration of education in years (OR 1.132) were predictors of osteoporosis.

Conclusions This study identified body weight as a modifiable risk factor of osteoporosis for post-menopausal women. Longitudinal observation of the same participants will be necessary to confirm these findings.

Keywords Age · Body size · Bone density · Speed of sound · The Philippines · Urban women

\section{Introduction}

Osteoporosis affects the bones, making them thin and fragile and putting them at increased risk of fracture. This condition is more common among the elderly women, and osteoporotic fracture can result in patients becoming bedridden [1]. Johnell et al. estimated that there were 9.0 million osteoporotic fractures in the year 2000 world wide, and the prevalence in South East Asia accounted for 15.3\% of the world occurrence [2]. Many factors have been associated with low bone mass that contributes to the development of osteoporosis; however, the high longevity, low calcium intake, and increasingly urban lifestyle of Filipino women are indicators that the prevalence of osteoporosis needs to be assessed in this group [1].

In 2002, the life expectancy at birth for Filipino women was 71.7 years and the healthy life expectancy was 
61.5 years [3]. Therefore, approximately 10 years of a Filipino woman's life was estimated to be affected by disability. According to a 1991 survey carried out at a Filipino orthopedic hospital, $62.9 \%$ of patients aged 50 years and over who had been admitted for fracture suffered from osteoporosis [4]. In addition, the reported calcium intake per person per day in the Philippines, according to the Sixth National Nutrition and Health Survey in the year 2003 , was $440 \mathrm{mg}$, which was only $57 \%$ of the recommended nutritional intake for Filipinos [5]. Although these evidences have hinted at the potential prevalence of osteoporosis in non-institutionalized post-menopausal women, few published studies have investigated the community-based bone-health status of Filipino women.

An urban lifestyle has been reported as a risk factor of low bone mass in several studies in Western countries [6]. In addition, a comparative study of four Asian countries reported that the prevalence of hip fracture was high in urbanized countries [7]. Previous studies in South East Asian countries showed that urbanization did not always negatively affect bone mineral density (BMD) $[8,9]$. However, a study of women in an urban low-income area of India reported that the BMD measured using dual energy X-ray absorptiometry (DXA) at three sites was much lower than that reported for developed countries [10]. The Philippines is a highly urbanized country in South East Asia, with nearly $60 \%$ of the population living in urban areas, $44 \%$ of which are slum dwellers [11]. An assessment of the bone-health status of urban Filipino women is therefore of particular importance in a public-health context.

The measurement of BMD is the primary predictor of fracture risk in the elderly $[12,13]$. However, routine measurements of BMD are not feasible in developing countries because of limited resources [14]. Identifying the risk factors for osteoporosis in order to plan preventive programs is thus of particular importance in developing countries. However, few studies have investigated the risk factors for osteoporosis in non-institutionalized Filipino women. Such factors are likely to be both genetic and environmental. The current study investigated the effects of age, body size, reproductive and lactating history, lifestyle, and socio-demographic factors on osteoporosis development in post-menopausal women $[9,15]$. The diagnostic criteria for pre-menopausal osteoporosis and the risk factors for osteoporosis in young women have not yet been established [16]. Consequently, the current cross-sectional study assessed the prevalence of osteoporosis in postmenopausal Filipino women using quantitative ultrasonic bone densitometry, and investigated the predictors of osteoporosis in an urban community setting. This initial trial was intended to allow a practical strategy to be designed in order to improve the health of urban Filipino women.

\section{Materials and methods}

Study site and participants

This study was carried out from December 2006 to January 2007 at a Barangay (which is the smallest administrative area in the Philippines) of one District with a high population density in urban area of Davao. With a population of 1.47 million individuals, according to the 2000 census, Davao is the second largest city after Manila in the Philippines [17].

The study site comprised five Sitios (blocks) around a Barangay hall. To determine the young adult mean (YAM) score of calcaneus speed of sound (SOS) which we measured to assess BMD, we recruited women aged 20 year and over. We could not determine the precise number of adult female residents within the five Sitios, as the residential registration system was under reform; however, the total household number was reported to be 924 , and the total population within the five Sitios was estimated to be 4200 , according to the Barangay office. We therefore aimed to survey a minimum of 924 women aged 20 years and over, residing within the five Sitios, so that roughly one adult free-ambulatory woman from each household could participate in the study. The Barangay Health Workers, who are volunteer community health workers of the Philippines, assisted with the recruitment process.

\section{Data collection and measures}

Data collection was performed at the Barangay hall after written consent was obtained from each of the participants. Experienced health workers were assigned to data collection, and a Filipino medical doctor supervised the procedure.

\section{(1) Face-to-face interview}

The face-to-face interview was conducted using a structured questionnaire that included items on home address, date of birth, reproductive and lactation history, lifestyle, and socio-demographic status in reference to previous studies. Ever diagnosed with osteoporosis or not was questioned, as well. Pregnancy and/or lactation status and a history of medical and drug administration that would affect BMD were also queried; individuals with these characteristics were to be excluded from the analysis in order to assess the bone-health status of healthy subjects $[9,15,18,19,20]$.

The questions on reproductive and lactation history included age of menarche, frequency of delivery, frequency of lactation and average months of lactation per child, history of menstrual disorder while of reproductive age, history of oral contraceptive use, history of estrogen 
replacement therapy, and pre/post-menopausal status. Menopause was defined as when a subject was aged 45 years or over and had not menstruated for at least 12 months [21].

The lifestyle questions included current smoking, daily alcohol intake, use of calcium supplementation, routine exercise status during the past 12 months (including frequency per week, average duration in minutes per exercise session, and type of exercise), and lifelong physical occupational status, all of which are considered to affect BMD $[9,15]$. The lifelong physical occupational status was defined as the occupation that the individual engaged in most frequently during her life, and was categorized as heavy labor (such as farming), domestic labor (such as house wife), or sedentary labor (such as office work) [9]. Socio-demographic factors can indirectly affect human health [22]. Thus, the socio-demographic questions included duration of education in years as the school educational attainment and total family income per person in 2005. The medical and drug administration histories included diabetes mellitus, cancer, thyrotoxicosis/ parathyrotoxicosis, chronic liver or kidney diseases, and rheumatoid arthritis, as well as corticosteroid administration. The questionnaire was written in English, translated into Bisaya and back- translated by different individuals.

\section{(2) Anthropometry}

Body height and weight were measured according to the World Health Organization (WHO) protocols [23]. The electronic standiometer measured 1-mm increments (DSN90; KDS Co., Kyoto, Japan). The weight scale used 100-g units (mechanical scale, model 3p7044; Detecto, Webb City, MO, USA). The body mass index (BMI) was calculated as the ratio of weight $(\mathrm{kg})$ to height $(\mathrm{m})$ squared. We used the WHO classification of BMI to identify the BMI status of the women as follows: underweight (BMI $<$ $18.5)$, normal $(18.5 \leq \mathrm{BMI}<25)$, overweight $(25 \leq \mathrm{BMI}<30)$, and obese $(\mathrm{BMI} \geq 30)[24]$.

\section{(3) Assessment of BMD}

We measured the SOS (in $\mathrm{m} / \mathrm{s}$ ) at the right calcaneus. DXA of the central skeleton is recognized as the 'gold standard' for BMD measurement [1]; however, the necessary equipment is not readily available at the community level in the Philippines [14]. The use of quantitative ultrasound (QUS) equipment for estimating BMD has been increasingly accepted as a diagnostic technique for the assessment of osteoporosis $[25,26]$. We therefore, measured the SOS of women aged 20 and over using a portable quantitative ultrasonic bone densitometer with a gelcoupled system (CM-100; Furuno Electric Co., Nishinomiya, Japan) in a temperature-controlled environment (26 \pm $1{ }^{\circ} \mathrm{C}$ ) in order to estimate the BMD.
The movable cylinder of the CM-100 can be used to hold the heel of each subject in position, in conjunction with a fixed cylinder. The sound wave passes from one transducer located in the fixed cylinder through the subject's heel to another transducer in the movable cylinder. One measurement takes approximately 10 seconds. A higher value is associated with a lower risk of osteoporosis.

Yo and Kishimoto [27] previously tested and confirmed the short term reproducibility of the results produced with this device, by calculating the coefficients of variation for the apparatus using both the phantom technique and healthy human subjects. The precision error was below $0.2 \%$ using the phantom technique and $0.5 \%$ in the healthy human subjects. The performance of the device was also compared with DXA. The SOS measured by the CM-100 correlated with BMD of both the calcaneus $(\mathrm{r}=0.77)$ and the lumber spine $(r=0.65)$ [27]. The study of Takaishi, et al. supported the result [28]. In addition, the areas under the ROC curves of SOS measured by the CM-100 and calcaneus BMD measured by DXA did not demonstrate any significant differences in predicting osteoporosis diagnosed using the lumber spine BMD measured by DXA [27].

Before starting the first measurement on each survey day, we performed a quality assurance phantom scan to check the device calibration.

\section{Statistical analysis}

To determine the YAM-SOS score, the mean SOS values among the age groups classified in 10 year increments were compared. The $T$-score was calculated using the YAM and the standard deviation (SD) as the maximum bone mass achieved by young healthy Filipino women using the following formula: (Individual SOS-YAM)/YAM SD [9]. The reference value used to determine the osteoporosis status was derived from Kishimoto et al. [29]. The study prepared sensitivity and specificity curves of the CM-100 in order to determine the cut-off value for discriminating between women with and without vertebral fracture. The sensitivity curve intersected with the specificity curve at $1479 \mathrm{~m} / \mathrm{s}(-1.79 \mathrm{SD}$ of YAM). Thus, the $T$-score for diagnosing osteoporosis was defined as below -1.79 . The ROC curve analysis demonstrated that there was no significant difference of sensitivity between the cut-offs of SOS by CM-100 and lumber spine BMD by DXA for predicting vertebral fracture [29]

The descriptive data are presented as the means, medians, or percentages. To compare the distributions of variables in the different age groups, we used $t$-tests, Bonferroni's tests following analysis of variance (ANOVA), Mann-Whitney $U$-tests, and Chi-square tests, as appropriate. To identify the variables that predicted osteoporosis, we performed binary logistic regression analysis. Initially, 
univariate analysis was performed to calculate the crude odds ratio (OR) and 95\% confidence interval (CI) for osteoporosis. Next, stepwise multiple logistic regression analysis was performed using backward elimination with the likelihood ratio test to identify significant independent variables for osteoporosis. All the significant and non-significant variables in the univariate analysis were subjected to backward elimination. The level of significance was $<0.05$ in two tailed tests. Dr. SPSS 2 for Windows (SPSS Japan Inc. Tokyo) software was used for statistical analysis.

\section{Ethical considerations}

All participants were informed of the purpose of the study, the safety of SOS measurements, the measures for the protection of privacy, the voluntary nature of participation, and their freedom to withdraw from the study. They were also informed that publication of the study results would be for academic and public-health purposes alone. Informed consent was obtained from all of the participants. This study was approved by the Ethical Committee of Biomedical Research, Ochanomizu University, Tokyo, Japan.

\section{Results}

In total, 1,151 women from the five Sitios participated in the survey. The number of participants in each 10-year age category were as follows: 187 in their 20s, 271 in their 30s, 259 in their 40s, 245 in their 50s, 129 in their 60s, 47 in their $70 \mathrm{~s}$, and 13 in their $80 \mathrm{~s}$. Women who reported a history of chronic diseases and corticosteroid drug administration, as well as those who were pregnant and/or lactating, were excluded; this left 905 women whose SOS data were used to define YAM and calculate the $T$-score. Table 1 shows the mean SOS according to the age groups. The highest mean SOS occurred in women in their 20 s, and the values gradually declined with age. There was a significant difference in the mean SOS between women in their 20s and those in their 30s (Table 1). Thus, the peak SOS value of $1,538.5(\mathrm{SD} \pm 33.1)$ in the group aged 20 to 29 years was defined as the YAM.

We excluded 566 pre-menopausal women. Thus, the final data used to identify the prevalence of osteoporosis and the associated risk factors came from 339 postmenopausal women. The crude prevalence of osteoporosis was $19.8 \%$. The prevalence for each age group was as follows: $3.7 \%$ in the $40 \mathrm{~s}, 9.9 \%$ in the $50 \mathrm{~s}, 13.8 \%$ in the $60 \mathrm{~s}$, $68.3 \%$ in the $70 \mathrm{~s}$, and $100 \%$ in the $80 \mathrm{~s}$. Of the 339 women, five $(1.5 \%)$ had previously been diagnosed with osteoporosis. The mean $( \pm \mathrm{SD})$ SOS values of women with and without osteoporosis were $1467.5( \pm 9.8)$ and 1512.0 ( \pm 22.8$)$, respectively.
Table 1 Mean Speed of Sound (SOS) value in age groups

\begin{tabular}{lllll}
\hline Age & $\mathrm{n}$ & Mean SOS & $\mathrm{n}=905$ & \\
\cline { 3 - 5 } & & & $\pm \mathrm{SD}$ & $p$ \\
\hline $20-29$ & 130 & 1538.5 & \pm 33.1 & - \\
$30-39$ & 213 & 1526.9 & \pm 31.3 & 0.005 \\
$40-49$ & 217 & 1522.9 & \pm 28.1 & $<0.001$ \\
$50-59$ & 204 & 1512.0 & \pm 25.9 & $<0.001$ \\
$60-69$ & 91 & 1501.8 & \pm 21.7 & $<0.001$ \\
$70-79$ & 41 & 1474.5 & \pm 19.4 & $<0.001$ \\
$80-89$ & 9 & 1460.6 & \pm 10.1 & $<0.001$ \\
\hline
\end{tabular}

The $p$ - value shows the level of significance of the difference in mean SOS between 20s age group and each of other age groups compared using Bonfferoni's test following ANOVA.

The different distributions of the anthropometric, reproductive, socio-demographic, and lifestyle variables of the participants with and without osteoporosis are summarized and crude OR and $95 \% \mathrm{CI}$ of each variable for osteoporosis are presented in Table 2.

In total, $55.5 \%$ of the women lived below the US\$1 per person per day threshold defined by the World Bank as the level of absolute poverty in low-income countries [30], and $27.7 \%$ lived on US\$1 to $\$ 2$ per person per day. When duration of education was categorized to 3 groups according to the school system of the Philippines, $36 \%$ of women were classified as primary level (0 to 6 years), $31 \%$ as high school level (7 to 10 years), and $33 \%$ as college level or above (11 years and over). The majority of the women engaged in domestic labor and less than $5 \%$ were engaged in heavy labor among all of the age groups. The most common types of exercise were walking $(30.7 \%)$ and stretching (12.4\%), while the other types were negligible. The percentages of women who exercised for an average of 30 minutes and over per session and who exercised 7 days a week were $14.7 \%$ and $29.8 \%$, respectively. The prevalence of estrogen replacement therapy or use of calcium supplementation was negligible.

Several variables were distributed differently by age group. The mean body height, mean body weight, and mean BMI were highest in those aged in their 40s and gradually declined with advancing age. The mean $( \pm \mathrm{SD})$ body heights of those aged in their 40 s and 80 s were 152.7 $( \pm 5.7) \mathrm{cm}$ and $147.7( \pm 6.5) \mathrm{cm}$, respectively. The mean body weights of those aged in their $40 \mathrm{~s}$ and 80 s were 60.0 $( \pm 13.4) \mathrm{kg}$ and $44.1( \pm 6.7) \mathrm{kg}$, respectively. The mean BMIs of those aged in their $40 \mathrm{~s}$ and $80 \mathrm{~s}$ were $25.8 \pm 5.0$ and $20.2 \pm 2.9$, respectively. We identified $7.1 \%$ of the postmenopausal women as having low BMI, $49.6 \%$ as normal, $33.6 \%$ as overweight, and $9.7 \%$ as obese. The prevalence of overweight and obese women was $50.0 \%$ among those in 
Table 2 Anthropometric, reproductive, socio-demographic, and lifestyle characteristics of 339 post-menopausal women with and without osteoporosis and crude odds ratios (ORs) for osteoporosis

\begin{tabular}{|c|c|c|c|c|c|c|}
\hline \multirow[t]{2}{*}{ Variables } & \multicolumn{2}{|c|}{ With osteoporosis } & \multicolumn{2}{|c|}{ Without osteoporosis } & \multirow[t]{2}{*}{ OR } & \multirow[t]{2}{*}{$95 \% \mathrm{CI}$} \\
\hline & Mean & $\pm \mathrm{SD}$ & Mean & $\pm \mathrm{SD}$ & & \\
\hline Body height $(\mathrm{cm})$ & 148.6 & \pm 5.9 & 150.4 & \pm 5.3 & 0.940 & $(0.893-0.989)$ \\
\hline Body weight (kg) & 49.4 & \pm 10.3 & 57.1 & \pm 11.2 & 0.932 & $(0.905-0.959)$ \\
\hline Body Mass Index (BMI) $\left(\right.$ weight $_{k g} /$ height $\left._{m}^{2}\right)$ & 22.3 & \pm 4.2 & 25.2 & \pm 4.3 & 0.846 & $(0.787-0.909)$ \\
\hline \multirow[t]{2}{*}{ Age of menarche } & 14.4 & \pm 1.7 & 13.9 & \pm 1.8 & 1.183 & $(1.015-1.378)$ \\
\hline & Median & {$[25 \%, 75 \%]$} & Median & {$[25 \%, 75 \%]$} & & \\
\hline Total delivery frequency & 6 & {$[4,8]$} & 4 & {$[3,6.75]$} & 1.130 & $(1.034-1.235)$ \\
\hline Total lactation duration in months & 72 & {$[21,96]$} & 36 & {$[6,84]$} & 1.004 & $(1.000-1.008)$ \\
\hline Age in 1 year increments & 71 & {$[59,74]$} & 56 & {$[53,62]$} & 1.163 & $(1.119-1.210)$ \\
\hline Family income/person in the year 2005 (US\$) ${ }^{a}$ & 300 & {$[160,600]$} & 343 & {$[189,600]$} & 1.000 & $(1.000-1.000)$ \\
\hline Duration of education in years & 7 & {$[6,14]$} & 10 & {$[6,13]$} & 0.972 & $(0.907-1.042)$ \\
\hline \multirow[t]{2}{*}{ Total routine exercise minutes/week during past 12 months } & 30 & {$[0,90]$} & 0 & {$[0,105]$} & 1.000 & $(0.999-1.001)$ \\
\hline & $\mathrm{n}$ & $(\%)$ & $\mathrm{n}$ & $(\%)$ & & \\
\hline Menstrual disorder while of reproductive age "Yes" & 4 & $(6.2)$ & 22 & $(8.1)$ & 0.742 & $(0.247-2.333)$ \\
\hline History of oral contraceptive use for 1 year and over "Yes" & 2 & $(3.0)$ & 36 & $(13.2)$ & 0.202 & $(0.047-0.860)$ \\
\hline \multicolumn{7}{|l|}{ Lifelong physical occupation } \\
\hline Heavy labor & 1 & $(1.5)$ & 11 & $(4.0)$ & 1.000 & - \\
\hline Domestic work & 54 & $(80.6)$ & 209 & $(76.8)$ & 2.814 & $(0.358-22.058)$ \\
\hline Sedentary work & 12 & $(17.9)$ & 52 & (19.1) & 2.511 & $(0.298-21.186)$ \\
\hline Daily alcohol intake "Yes" & 5 & $(7.5)$ & 29 & $(10.7)$ & 0.678 & $(0.251-1.818)$ \\
\hline Current smoking "Yes" & 10 & $(14.9)$ & 31 & $(11.4)$ & 1.367 & $(0.632-2.943)$ \\
\hline
\end{tabular}

${ }^{\text {a }}$ US $1 \$$ was estimated as 50 pesos.

their $40 \mathrm{~s}$; this declined to $0 \%$ among those in their $80 \mathrm{~s}$, $22.2 \%$ of whom were underweight. The percentage of the participants reporting a history of oral contraceptive use for 1 year or over was the highest among those in their $40 \mathrm{~s}$ (19.2\%) and declined with advancing age. Conversely, the age of menarche, delivery frequency, and total lactation duration (that is, the average lactation duration per child multiplied by the frequency of lactation) were lower in the younger age groups than in the older groups. The percentage of older women who had undertaken routine exercise during the past 12 months was higher than younger women $(77.8 \%$ in the $80 \mathrm{~s}$ age group versus $34.6 \%$ in the 40 s age group). The percentage of women who reported sedentary labor as their lifelong physical occupation was $23.1 \%$ in the $40 \mathrm{~s}$ age group and gradually declined to $0 \%$ in the 80 s age group. The median $(25 \%, 75 \%)$ family income per person in 2005 was US $\$ 400(253,574)$ in the 40 s age group and gradually fell to US $\$ 253(155,360)$ in the 80 s age group. The median $(25 \%, 75 \%)$ duration of education in years was $10(9,14)$ for those in their 40 s and gradually declined to $6(4.5,8.5)$ for those in their $80 \mathrm{~s}$. There were no age-related trends in the prevalence of the history of menstrual disorder while of reproductive age, daily alcohol intake, and current smoking.

The age in one year increments, body weight, and duration of education in years emerged as the predictors for osteoporosis in the final model of logistic regression analysis (Table 3).

\section{Discussion}

In the current community-based cross-sectional assessment of bone-health status among urban Filipino women, 19.8\% of the post-menopausal participants were estimated to have osteoporosis, while only $1.5 \%$ reported a previous disgnosis with osteoporosis. The independent predictors of osteoporosis in these women were advancing age, lower body weight, and higher educational attainment.

The extremely low osteoporosis diagnosis rate prior to this survey suggests difficulties in access to BMD measurements, as mentioned in a previous Filipino study [14]. The lack of affordability of these measurements for women below the poverty line would be an additional factor. We therefore propose that measures to prevent osteoporosis should be advocated over diagnosis and treatment in

Table 3 Predictors and adjusted odds ratios (ORs) for osteoporosis in post-menopausal women $(n=339)$

\begin{tabular}{lll}
\hline Variables & OR & $(95 \% \mathrm{CI})$ \\
\hline Age in 1 year increments & 1.168 & $(1.115-1.224)^{\mathrm{a}}$ \\
Body weight $(\mathrm{kg})$ & 0.954 & $(0.923-0.987)^{\mathrm{b}}$ \\
Duration of education in years & 1.132 & $(1.036-1.237)^{\mathrm{c}}$
\end{tabular}

a Adjusted for body weight $(\mathrm{kg})$ and duration of education in years

b Adjusted for age in 1 year increments and duration of education in years

c Adjusted for body weight $(\mathrm{kg})$ and age in 1 year increments 
communities where the majority of residents live on lowincomes.

Low body weight predicted osteoporosis in our study as also reported for large epidemiological studies in the USA and France. These studies suggested that heavier individuals might put more strain on their bones as weight-bearing exercise increased the BMD [31]. Although body weight and BMI are different indicators, the Sixth National Nutrition and Health Survey of the Philippines revealed that the prevalence of overweight and obese women aged 20 years and over increased from $18.6 \%$ in 1993 to $27.1 \%$ in 2003 . By contrast, $28.1 \%$ of women aged 70 years and over were underweight in 2003 [32, 33]. Our study participants showed a similar trend. Overweight status is a known risk factor for the development of cardiac diseases and/or type 2 diabetes [34]. However, based on our findings, recent promotion of weight-loss schemes in the Philippines requires careful consideration with respect to the prevention of osteoporosis.

Routine exercise did not protect against osteoporosis development in our participants, perhaps because moderate walking without weight-bearing exercise was most common and might not be sufficient to improve BMD. Estimating the minutes per exercise session based on a questionnaire interview might have caused random variations in the participants' responses as reported in other studies [35]. A systematic review paper of exerciseintervention trials concluded that moderate daily walking for 30 minutes combined with weight-bearing exercises twice weekly prevented bone loss among early postmenopausal women [36]. For older women, combined weight-bearing exercise was reported to be effective in improving BMD [37]. Such trials in other countries could be extended to urban Filipino women, in order to design programs to promote healthy bones.

The differences in socio-demographic status, reproductive history, and lifestyle among the age groups in our study suggest that gradual social transitions have affected the lives of urban Filipino women during the past 60 years. However, with the exception of educational attainment, these transitions did not significantly influence the prevalence of osteoporosis. The younger generation had higher educational attainment and higher SOS scores. When age and body weight were adjusted for, the women with higher educational attainment had a moderately higher risk of osteoporosis. Consistent with our results, a study of elderly Mexican-American women reported that the osteoporosis prevalence was greater among those with higher educational attainment [38]. By contrast, a study in Vietnam reported that higher educational attainment reduced the risk of osteoporosis [9]. The risk factors for osteoporosis might differ among different populations [15]; alternatively, educational attainment might have been a proxy for unmeasured factors that affected the SOS score in our study, because socio-demographic factors could influence human health by interacting with other factors [22]. Identifying the community-based risk factors for osteoporosis thus has intrinsic value.

To our knowledge, this is the first study to assess the bone-health status of healthy Filipino women dwelling in an urban community in which the majority lived on lowincomes. However, several points should be considered when interpreting the present data. First, the study could not establish the cause-effect relationships between the variables because of its cross-sectional design; nonetheless, the results point to risk factors for osteoporosis development in urban Filipino women. Second, we used a convenience sampling approach, which was not representative of all urban adult Filipino women, although it was an excellent method to investigate the health of under-studied urban women with low-incomes [39]. Third, the screening of women with a history of disease using face-to-face interviews was previously found not to endorse the accuracy of diagnosis where access to medical services was limited [40]; despite this, the interviewers and the interviewees made their best efforts to reach a common understanding on the diagnosis with the assistance of a Filipino physician. In addition, the $100 \%$ prevalence of osteoporosis in the $80 \mathrm{~s}$ age group could not be generalized because of the small sample size, though our current findings appeared to be reasonable in the light of the results of a previous study of Indian women from urban low-income communities [10]. Fourth and finally, we could not obtain dietary data because validated food frequency questionnaire (FFQ) to measure usual calcium intake was not available. Milk and milk products are mostly imported [41] and not affordable for individuals with low-incomes. Therefore, applying the FFQ developed for other countries was not possible. We attempted 24-hours dietary recall method in our preliminary survey; however, we found that the traditional shared-plate eating style made estimating the amount of food consumed difficult for most women. Although we could not include dietary data in our analysis, the findings of our preliminary survey will allow us to explore a direct method for dietary data collection based on smaller sample sizes in future studies.

In summary, this primary community-based assessment of bone-health status in urban Filipino women concluded that advancing age, lower body weight, and higher educational attainment were predictors of the development of osteoporosis among post-menopausal women. Our results highlight the need for an osteoporosis prevention program for urban Filipino women in low-income areas. Prospective longitudinal observation of the participants of the present study could confirm the effects of age, body weight, and educational background on osteoporosis development, and allow its role in fracture risks to be evaluated. 
We believe that our current findings will be beneficial in determining the prevalence and risk factors for osteoporosis in a non-institutionalized population in the Philippines.

Acknowledgments This study would not be possible without the technical support of the health workers of Japan Phillippine Volunteer Association who assisted the survey. The authors appreciate them.

\section{Conflict of interest None.}

Open Access This article is distributed under the terms of the Creative Commons Attribution Noncommercial License which permits any noncommercial use, distribution, and reproduction in any medium, provided the original author(s) and source are credited.

\section{References}

1. World Health Organization (WHO) (2003) Prevention and Management of Osteoporosis. WHO Technical Report Series 921. Available at: http://whqlibdoc.who.int/trs/WHO_TRS_921. pdf. Accessed 20 November 2006

2. Johnnel O, Kanis JA (2006) An estimate of the worldwide prevalence and disability associated with osteoporotic fractures. Osteoporos Int 17:1726-1733

3. WHO (2004) The World Health Report http://www.who.int/whr/ 2004/annex/topic/en/annex 4 en.pdf. Accessed 6 February 2006

4. Osteoporosis Society of the Philippines Foundation Inc (OSPFI) (2006) OSPFI's fight against osteoporosis in the Philippines. Available at: http://www.osteofound.org/member-societies/society. php?id=93. Accessed 28 June 2006

5. Food and Nutrition Research Institute (FNRI) (2006) FNRI-DOST Study notes Filipinos have low calcium intakes. Available at: http://www.fnri.dost.gov.ph/wp/lowcalciumintake.htm. Accessed 20 August 2006

6. Meyer HE, Berntsen GKR, Søgaard AJ et al (2004) Higher bone mineral density in rural compared with urban dwellers The NOREPOS Study. Am J Epidemiol 160(11):1039-1046

7. Lau EMC, Lee JK, Suriwongpaisal P et al (2001) The incidence of hip fracture in four Asian countries: the Asian Osteoporosis Study (AOS). Osteoporos Int 12:239-243

8. Pongchaiyakul C, Nguyen TV, Kosulwat V et al (2005) Effect of urbanization on bone mineral density: A Thai epidemiological study. BMC Musculoskelet Disord DOI: 10. 1186/1471-2474-6-5

9. Hien VTT, Khan NC, Lam NT et al (2005) Determining the prevalence of osteoporosis and related factors using quantitative ultrasound in Vietnamese adult women. Am J Epidemiol 161 (9):824-830

10. Shatrugna V, Kulkarni B, Kumar PA et al (2005) Bone status of Indian women from a low-income group and its relationship to the nutritional status. Osteoporos Int 16:1827-1835

11. United Nations Human Settlements Programme (UN-HABITAT) (2003) Slums of the World: The face of urban poverty in the new millennium? Available at: http://www.unhabitat.org/publication/ slumreport.pdf. Accessed 31 August 2005

12. Kanis JA, Glüer CC, for the Committee of Scientific Advisors, International Osteoporosis Foundation (2000) An update on the diagnosis and assessment of osteoporosis with densitometry. Osteoporos Int 11:192-202

13. Marshall D, Johnell O, Wedel H (1996) Meta-analysis of how well measures of bone mineral density predict occurrence of osteoporotic fractures. BMJ 312:1254-1259
14. Torralba TP (2004) Clinical management of osteoporosis in the Philippines. Clin Calcium 14(9):134-137

15. Lim PS, Ong FB, Adeeb N et al (2005) Bone health in urban midlife Malaysian women: risk factors and prevention. Osteoporos Int 16:2069-2079

16. Lewiecki EM (2005) Premenopausal bone health assessment. Curr Rheumatol Rep 7:46-52

17. Regional Development Council XI (RDC XI), Regional Statistical Coordination Committee XI, \& National Statistical Coordination Board XI (2004) 2004 Edition of the Davao Region Statistical Yearbook. RDC XI, Davao City

18. Karlsson MK, Ahlborg HG, Karlsson C (2005) Maternity and bone mineral density. Acta Orthop 76(1):2-13

19. Gur A, Nas K, Cevik R (2003) Influence of number of pregnancies on bone mineral density in postmenopausal women of different age groups. J Bone Miner Metab 21:234-241

20. Fortney JA, Feldblum PJ, Talmage RV et al (1994) Bone mineral density and history of oral contraceptive use. J Reprod Med 39 (2):105-109

21. Ramos-Jalbuena J (1994) Climacteric Filipino women: a preliminary survey in the Philippines. Maturitas 19:183-190

22. Schrijvers CTM, Stronks K, van de Mheen HD et al (1999) Explaining educational differences in mortality: the role of behavioral and material factors. Am J Public Health 89 (4):535-540

23. WHO (1995) Physical Status: The Use and Interpretation of Anthropometry. WHO Technical Report Series 854. Available at: http://whqlibdoc.who.int/trs/WHO_TRS_854.pdf. Accessed 18 August 2007

24. WHO (2007) BMI classification. http://www.who.int/bmi/index. jsp?introPage=intro-3.html. Accessed 27 July 2007

25. Hans D, Dargent-Molina P, Schott AM et al, for the EPIDOS prospective study group (1996) Ultrasonographic heel measurements to predict hip fracture in elderly women: the EPIDOS prospective study. Lancet 348:511-513

26. Glüer C-C, Hans D (1999) How to use ultrasound for risk assessment: a need for defining strategies. Osteoporos Int 9:193195

27. Yo K, Kishimoto H (1997) Examination of the clinical usefulness of new ultrasonic bone density measurement equipment. (In Japanese) Osteoporosis Japan 5(4):813-822

28. Takaishi Y, Okamoto Y, Ikeo T et al (2005) Correlations between periodontitis and loss of mandibular bone in relation to systemic bone changes in postmenopausal Japanese women. Osteoporos Int 16:1875-1882

29. Kishimoto H, Yo K, Ohta H et al (2003) Reference and cut-off value of quantitative ultrasound measured by CM-100. (In Japanese) Osteoporosis Japan 11(2):307-310

30. World Bank (WB) (1990) World Development Report: Poverty. Available at: http://www-wds.worldbank.org/external/default/ WDSContentServer/WDSP/IB/2000/12/13/000178830 98101 903345649/Rendered/PDF/multi_page.pdf. Accessed 20 July 2007

31. Robbins J, Schott A-M, Azari R et al (2006) Body mass index is not a good predictor of bone density: results from WHI, CHS, and EPIDOS. J Clin Densitom 9(3):329-334

32. Dans AL, Morales DD, Velandria F et al (2005) National Nutrition and Health Survey (NNHeS): Atherosclerosis-related diseases and risk factors. Phil J Intern Med 43:103-115

33. Villavieja GM, Molano WL, Corazon MC et al (1997) Fourth National Nutrition Survey, Philippines, 1993 Part B. Anthropometric survey. Phil J Nutr 44(1 \& 2):34-48

34. Tanchoco CC, Cruz AJ, Duante CA et al (2003) Prevalence of metabolic syndrome among Filipino adults aged 20 years and over. Asia Pac J Clin Nutr 12(3):271-276

35. Heimmel J, Patel S, Cody R et al (2007) Evaluation of physical fitness in an ambulatory setting. Am J Obstet Gynecol 196:522. e1-522.e4 
36. Asikainen T-M, Kukkonen-Harjula K, Miilunpalo S (2004) Exercise for health for early postmenopausal women. Sports Med 34(11):753-778

37. Englund U, Littbrand H, Sondell A et al (2005) A 1-year combined weight-bearing training program is beneficial for bone mineral density and neuromuscular function in older women. Osteoporos Int 16:1117-1123

38. Tolea MI, Black SA, Carter-Pokras OD et al (2007) Depressive symptoms as a risk factor for osteoporosis and fractures in older Mexican American women. Osteoporos Int 18:315-322
39. Yach D, Mathews C, Buch E (1990) Urbanization and health: methodological difficulties in undertaking epidemiological research in developing countries. Soc Sci Med 31(4):507-514

40. Baltazar JC, Ancheta CA, Aban IB et al (2004) Prevalence and correlates of diabetes mellitus and impaired glucose tolerance among adults in Luzon, Philippines. Diabetes Res Clin Pract $64: 107-115$

41. Wiley AS (2007) The globalization of cow's milk production and consumption: Biocultural perspectives. Ecol Food Nutr 46: 281-312 